\title{
Induced haploinsufficiency of Kit receptor tyrosine kinase impairs brain development
}

\author{
Hitomi Aoki, ${ }^{1}$ Akira Hara, ${ }^{2}$ and Takahiro Kunisada ${ }^{1}$ \\ 'Department of Tissue and Organ Development and 'Department of Tumor Pathology, Gifu University Graduate School of \\ Medicine, Gifu, Japan.
}

\begin{abstract}
Kit receptor tyrosine kinase is highly expressed in the developing mammalian brain, yet little is known about its contribution to neural cell development and function. Here we introduced a brainspecific conditional Kit loss-of-function mutation in mice and observed severe hypoplasia of the central nervous system. This was accompanied by an increase in apoptotic cell death in the early embryonic brain and the gradual loss of the self-renewal capacity of neuronal stem/precursor cells. A single copy of the brain-specific conditional Kit loss-of-function allele resulted in the observed phenotype, including impaired in vitro differentiation of neural cells from Kit-haploinsufficient embryonic stem (ES) cells. Our findings demonstrate that Kit signaling is required for the early development of neural cells. This potentially novel Kit-haploinsufficient lethal phenotype may represent an embryonic lethal phenomenon previously unobserved because of its dominantly acting nature.
\end{abstract}

Conflict of interest: The authors have declared that no conflict of interest exists.

Submitted: April 5, 2017 Accepted: September 5, 2017 Published: October 5, 2017

\section{Reference information:} JCI Insight. 2017;2(19):e94385 https://doi.org/10.1172/jci. insight. 94385 .

\section{Introduction}

Kit receptor tyrosine kinase regulates a wide range of functions in various vertebrate cell lineages, including pigment cells, hematopoietic cells, germ cells, gastrointestinal cells, nerve cells, cardiovascular cells, and lung cells $(1,2)$. In these cell lineages, stem cells or the immediate descendant of stem cells are strictly dependent on Kit signaling for their survival, proliferation, and differentiation (3-5), as are embryonic stem (ES) cells (6). Kit was originally identified as a feline proto-oncogene. Cancer cells, such as those in gastrointestinal mesenchymal tumors and melanomas, were known to have a gain-of-function mutation in Kit, and anticancer drugs that specifically block Kit signaling are used to treat cancers with Kit mutations (1).

Kit protein forms a homodimer that binds the Kitl ligand (7). Heterodimers formed between wild-type and mutant Kit proteins show a considerable reduction of Kit tyrosine kinase activity. This loss of activity is seen in the semidominant inheritance of Kit-locus mutants, in which heterozygous loss-of-function mutations impair melanocyte development to produce white coat spotting $(7,8)$.

Kit mRNAs are highly expressed in many tissues, including the developing brain and adult brain (9-11), yet no clear developmental phenotype in the brain resulting from the loss of specific cell types or functions has been detected in Kit-mutant mice. Rather, only either subtle higher-level brain functions were affected, including spatial learning (9), or relatively minor perturbations to brain structure and biochemistry, including the axon guidance of commissural neurons (12), and the transduction properties of sensory neurons (13).

Here, we engineered a conditional loss-of-function Kit mutation into mice that allowed us to induce $K i t$ haploinsufficiency at specific points during development. Using this nongermline induction of Kit haploinsufficiency, we observed severe hypoplasia of the brain not previously reported in mouse Kit mutants. Our findings indicate that Kit expressed in the developing brain is important for proper brain development, and that many neural stem cell lineages are dependent on Kit at certain developmental stages of the brain.

\section{Results}

Conditionally induced haploinsufficiency of Kit receptor tyrosine kinase impaired in vitro neural cell differentiation from ES cells. We generated $(129 / \mathrm{SvJ} \times \mathrm{C} 57 \mathrm{BL} / 6) \mathrm{F} 1 \mathrm{ES}$ cell clones containing a floxed Kit allele $\left(\mathrm{Kit}^{2 l o x /+}\right)$ by conventional homologous gene recombination. In these ES cells, 2 loxP sites flank exon 10 of Kit, which encodes the transmembrane domain. Conditional deletion of exon 10 results in direct splicing of exon 9 to exon 11 and the generation of premature stop codons in exon 11 (14). After Cre recombination, the allele designated as $\mathrm{Kit}^{1 \mathrm{llox} /+}$ resembles the spontaneous $\mathrm{Kit}^{W}$ allele in which a mutation in the first nucleotide of 
intron 10 leads to the skipping of exon 10 in the mature transcript. In both cases, loss of the transmembrane region results in failure to transduce the signal evoked by Kitl (15). Kit ${ }^{2 l o x /+}$ ES clone 3-derived (14) $\mathrm{Kit}^{2 l o x /+}$ clonal mice were backcrossed with C57BL/6 mice for at least 5 generations, and were then crossed with Sox1-Cre mice, in which Cre recombinase protein was expressed under the control of the central nervous system-specific Sox1 promoter/enhancer sequence $(16,17)$. From the resulting Sox $1-\mathrm{Cre}$; Kit ${ }^{2 l o x /+}$ blastocysts, we established Sox1-Cre; Kit ${ }^{2 l o x /+}$ ES cell lines.

Control ES cell lines, such as Sox1-Cre; $\mathrm{Kit}^{+/+}$and $\mathrm{Cre}^{-} ; \mathrm{Kit}^{2 l o x /+}$, were differentiated into fully developed postmitotic neuronal class III $\beta$-tubulin-positive (Tuj $1^{+}$) neurons in PA6 stromal cell cultures (Figure 1A) and $80 \%$ to $90 \%$ of the ES cell-derived colonies contained Tuj $1^{+}$neurons. (Figure 1B). In contrast, the number of colonies containing Tuj1+ neurons from Sox1-Cre; Kit ${ }^{2 l o x /+}$ ES cell lines was significantly reduced in comparison with those from control ES cell lines (Figure 1B), and each colony contained a reduced number of Tuj $1^{+}$neurons (Figure 1A). No previously published Kit mutations have been reported to affect growth and differentiation of neural cells. As expected, germline Kit-null mutant ES cell lines established from both $\mathrm{Kit}^{W /+}$ and $\mathrm{Kit}{ }^{W / W}$ mice showed an emergence of Tuj1 $1^{+}$neurons and glial fibrillary acidic protein-positive $\left(\mathrm{GFAP}^{+}\right)$glial cells similar to those established from wild-type littermates (Figure 1C and D). Addition of wild-type recombinant Kitl protein to the Sox1-Cre; Kit ${ }^{2 l o x /+}$ ES cell culture restored the efficiency of neural cell differentiation to that of the control culture (Supplemental Figure 1; supplemental material available online with this article; https://doi.org/10.1172/ jci.insight.94385DS1), and this was reversed by the addition of the Kit antagonistic antibody ACK2 (Supplemental Figure 1), indicating that Kit signal reduction induced by Sox1-Cre-induced Kit haploinsufficiency is responsible for this phenomenon.

Sox1-Cre; $\mathrm{Kit}^{2 l o x /+}$ ES cells were established from fertilized eggs taken from viable, phenotypically normal pairs of Sox1-Cre and $\mathrm{Kit}^{2 l o x /+}$ mice. The $\mathrm{Kit}^{2 l o x / 2 l o x}$ homozygous mice were also all developmentally normal (14), indicating that it was very unlikely that the neuronal differentiation defect was introduced during the establishment of the ES cell strain. We found no mutations in the exons of either of the Kit alleles in clone $3 \mathrm{Kit}^{2 l o x /+}$ ES cells. Quantification of cell surface-resident Kit protein in the clone $3 \mathrm{Kit}^{2 l o x /+}$ ES cell line revealed it was reduced by approximately half, as expected (14). The haploinsufficient $K i t^{\text {llox/+ }}$ ES cells originating from Rosa26::rtTA; Colla1::tetO-Cre; Kit ${ }^{2 l o x /+}$ ES cells treated with doxycycline also generated comparable numbers of Tuj $1^{+}$and $\mathrm{GFAP}^{+}$colonies to those of controls (Supplemental Figure 2), further indicating the genetic integrity of clone $3 \mathrm{Kit}^{2 l o x /+} \mathrm{ES}$ cells.

Hypoplasia of the brain by the Sox1-Cre-induced Kit haploinsufficiency. The cross between Sox1-Cre and Kit ${ }^{2 l o x /+}$ mice generated no viable offspring with the Sox1-Cre; Kit ${ }^{2 l o x /+}$ genotype. Sox1-Cre; Kit $t^{2 l o x /+}$ embryos showed a reduction in the size of the forehead as early as E12.5 (Figure 2A, marked by the asterisks), and clear hypoplasia of the head region was evident at E15.5 (Figure 2B). Surviving Sox1-Cre; Kit ${ }^{2 l o x /+}$ fetuses at E18.5 showed the same hypoplastic features (Figure 2C) including eye defects in some individuals (Figure 2D). Penetrance of the brain hypoplasia phenotype in Sox1-Cre; Kit ${ }^{2 l o x /+}$ mice was $92.3 \%$ at E12.5 and 100\% thereafter (Supplemental Table 1). Expression of the endogenous Sox1 gene starts as early as E8.0 (18), and we observed a reduction of Kit mRNA expression in the Kit conditionally knocked out brain to half of that in controls as early as E10.5 to E18.5 (Figure 2E). The numbers of neural cells were markedly reduced in the brain and spinal cord of E12.5 Sox1-Cre; Kit $t^{2 l o x /+}$; Rosa26R-EYFP mice (Supplemental Figure 3A), and, as expected, cell surface Kit protein per cell decreased in EYFP-expressing neural cells (Supplemental Figure 3B).

E12.5 Sox1-Cre; $\mathrm{Kit}^{2 l o x /+}$ embryos showed a marked reduction in the size of the whole brain, including the telencephalon, diencephalon, mesencephalon, metencephalon, and myelencephalon (Figure 3, A-C). In particular, the reductions of the telencephalon and myelencephalon were considerable. Drastic hypoplasia of neural cells was also observed in the spinal cord of Sox1-Cre; Kit $t^{2 l o x /+}$ embryos (Figure 3D). Among the neural tissues that originate from Sox $1^{+}$precursors, dorsal root ganglia were found to maintain their absolute size in Sox1-Cre; Kit ${ }^{2 l o x /+}$ embryos (Figure 3D). Since only punctate Kit expression was observed in the dorsal root ganglia (9-11), conditional Kit deletion might have only a minor effect on their differentiation. It should be noted that the sizes of nasal chambers (Figure 3C), the tongue, and other non-neural organs in Sox1-Cre; Kit ${ }^{2 l o x /+}$ embryos remained comparable with those of the controls.

To understand the mechanisms underlying neural hypoplasia in Sox 1-Cre; $\mathrm{Kit}^{2 l o x /+}$ embryos, we investigated the proliferative characteristics of neural cells in the affected brain regions. In E12.5 embryos, proliferative cells expressing Ki67 and nestin were detected among the ependymal layer cells of the telencephalon both in Sox1-Cre; Kit $t^{2 l o x /+}$ and control brains (Figure 3E), while Tuj $1^{+}$postmitotic neurons in 
A

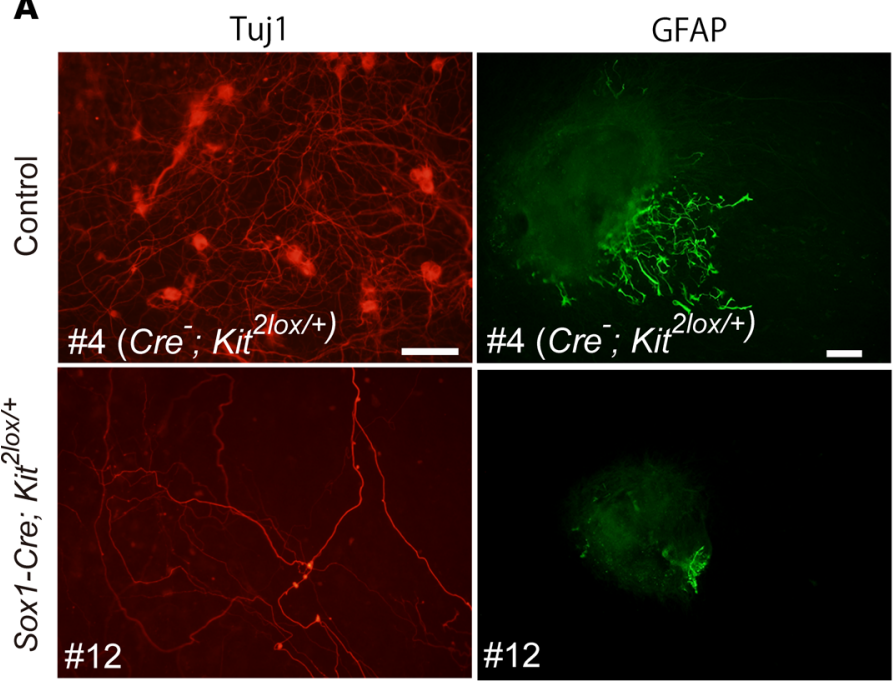

B
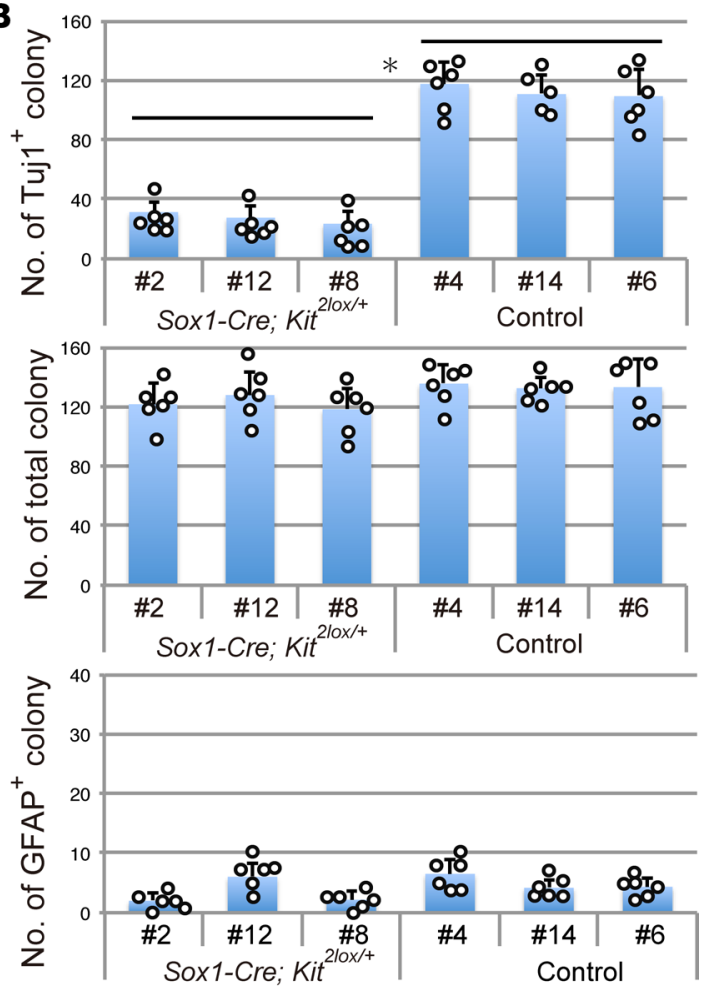

D
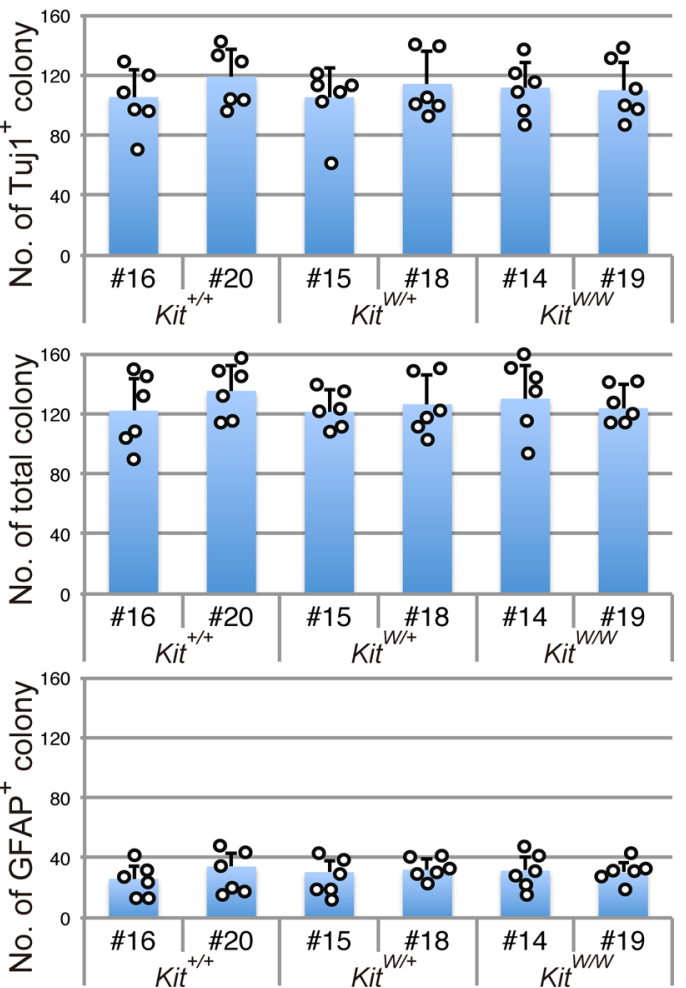

Figure 1. Defective in vitro differentiation of neural cells from Sox1-Cre; Kit ${ }^{2 l o x /+}$ ES cells. (A) In vitro-differentiated Tuj1+ neurons and GFAP+ glial cells from Sox1-Cre; Kit ${ }^{210 x /+}$ and control ES cell lines. (B) Quantification of colonies from 3 independently established Sox1-Cre; Kit2lox/+ and control ES cell lines. (C) Tuj1 ${ }^{+}$neurons and GFAP ${ }^{+}$glial cells differentiated from $\mathrm{Kit}^{\mathrm{W/+}}, \mathrm{Kit}^{\mathrm{W/W}}$, and littermate wild-type-derived ES cell lines. (D) Quantification of colonies from 2 independently established $\mathrm{Kit}^{\mathrm{W/+}}, \mathrm{Kit}^{\mathrm{W} / \mathrm{W}}$, and $\mathrm{Kit}^{+/+} \mathrm{ES}$ cells. Error bars show $\pm \mathrm{SD}\left(n=3\right.$ for each ES cell line). ${ }^{*} P<0.01$, by 2 -tailed Student's $t$ test. Scale bars: $100 \mu \mathrm{m}$. 

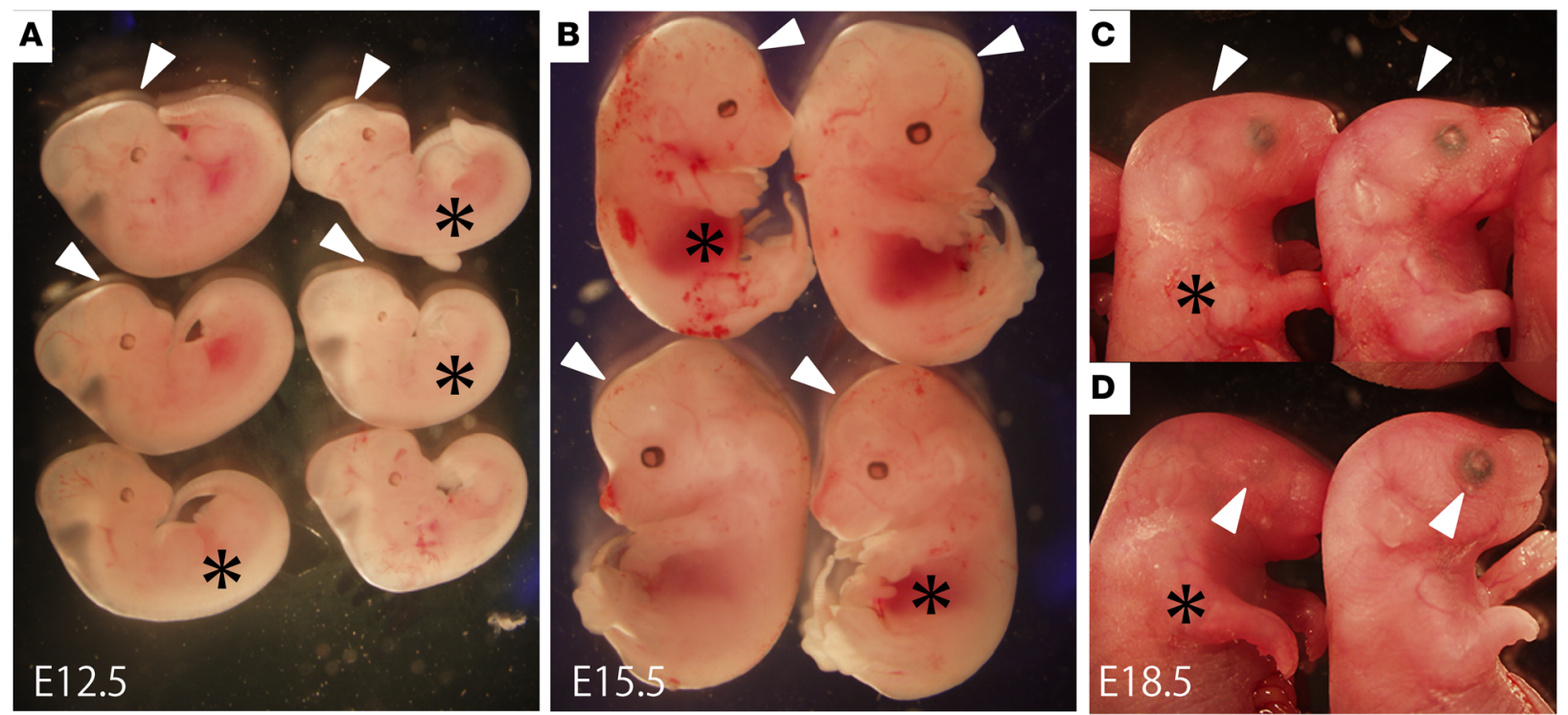

E
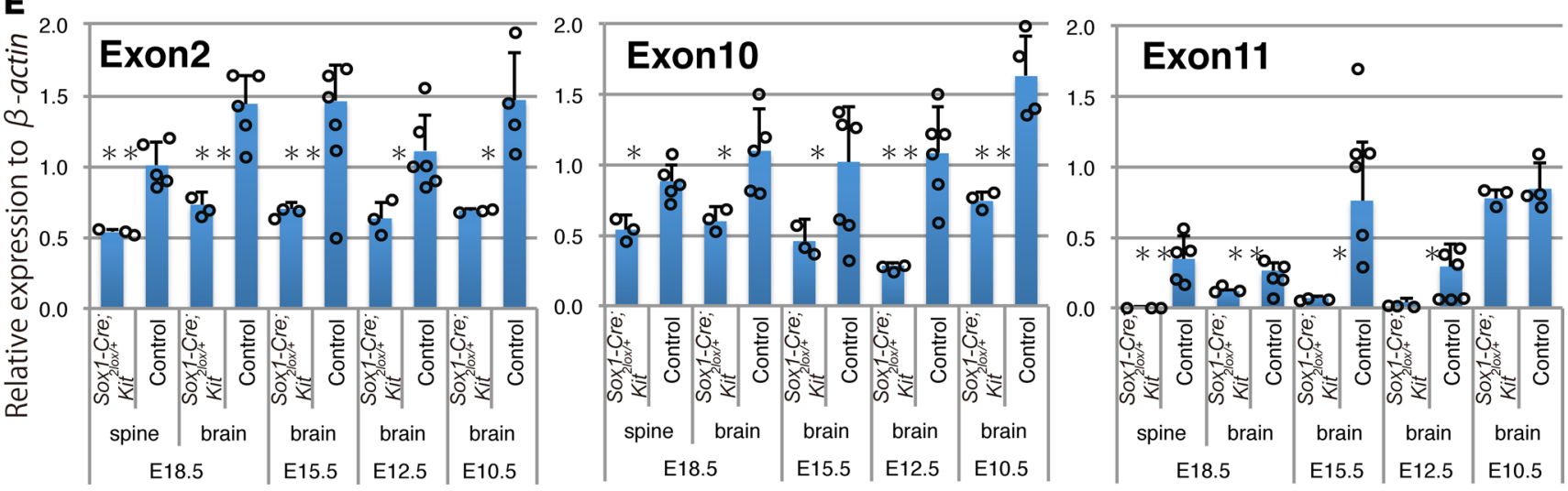

Figure 2. Hypoplasia of the brain observed in Sox1-Cre; Kit ${ }^{210 x /+}$ embryos. (A) Head morphologies of E12.5, (B) E15.5, and (C and D) E18.5 Sox1-Cre; Kit ${ }^{210 x /+}$ embryos are shown. Sox1-Cre; Kit ${ }^{2 l o x /+}$ embryos are indicated by asterisks. Regions indicating hypoplastic brains are indicated by arrowheads. (E) Expression of the Kit transcript was measured by RT-PCR from Sox1-Cre; Kit ${ }^{210 x /+}$ spine and brain tissues dissected at the indicated embryonic days. Error bars show \pm SD ( $n=3$ for each genotype group). ${ }^{*} P<0.05$ and ${ }^{* *} P<0.01$ by 2 -tailed Student's $t$ test.

that area were markedly reduced in Sox1-Cre; Kit $t^{2 l o x /+}$ brains (Figure 3E). TUNEL ${ }^{+}$apoptotic cells were frequently detected only in Ki67 $7^{+}$and nestin ${ }^{+}$areas of Sox1-Cre; Kit ${ }^{2 l o x /+}$ brains (Figure 3E). A similar reduction in postmitotic neurons was observed in most brain regions including the diencephalon, mesencephalon, metencephalon, and myelencephalon (Supplemental Figure 4). A comparable number of $\mathrm{Ki} \mathrm{7}^{+}$cells was observed among the ependymal layer cells of the spinal cord in Sox1-Cre; Kit $t^{2 l o x /+}$ and control mice (Figure 3F). The reduction in the total number of Tuj $1^{+}$postmitotic cells seems to be responsible for the drastic reduction in the total size of the spinal cord of Sox1-Cre; Kit $2^{2 b x /+}$ mice (Figure $3 \mathrm{~F}$ ). Most of the TUNEL ${ }^{+}$cells were detected in the ependymal layer, but not in the mantle layer (Figure 3F). Both in the telencephalon and the spinal cord, TUNEL ${ }^{+}$cells were found in regions of the ependymal layer in close proximity to the ventricle (Figure 3, E and F). The size of the eyes was also reduced in Sox1-Cre; Kit $t^{2 l o x /+}$ mice (Figure $3 \mathrm{G}$ ). $\mathrm{Ki} 67^{+}$cells were distributed in the entire developing retina and also in the lens fiber precursor cells both in Soxl-Cre; Kit $210 x /+$ and control embryos (Figure $3 \mathrm{G})$; however, Tuj1 ${ }^{+}$neurons were greatly reduced in Sox1-Cre; Kit ${ }^{2 l o x /+}$ retinas. Apoptotic cells were evident within the retina and lens fiber cells (Figure 3G). These observations suggest that undifferentiated neural stem cells were maintained and not apoptotic in the E12.5 Sox1-Cre; Kit $t^{2 l o x /+}$ brain, but that the proliferation of transient amplifying cells directly producing postmitotic neurons was prevented by apoptosis in the Sox1-Cre; $\mathrm{Kit}^{2 l o x /+}$ brain. The resulting reduction in the total number of mature neural cells is likely the cause of hypoplasia in the brain and the other affected organs. 

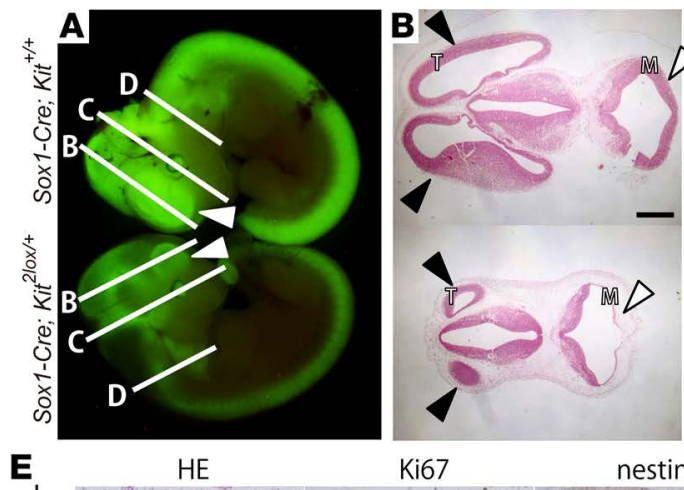

HE

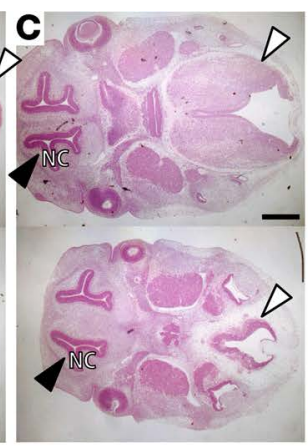

nestin

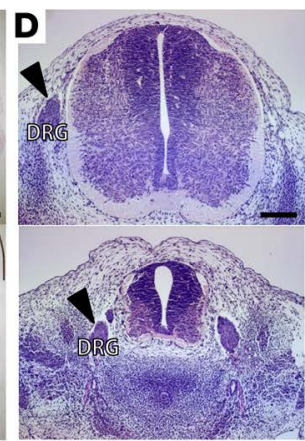

TUNEL

TUNEL

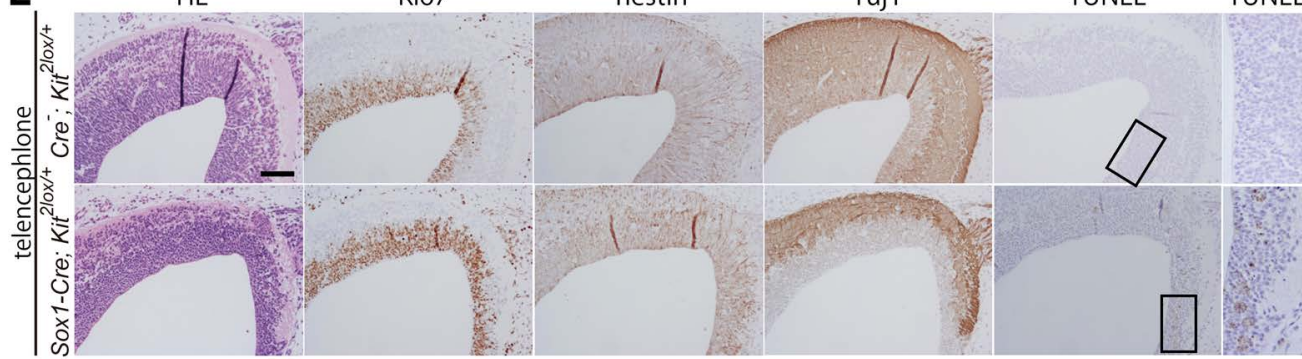

F|

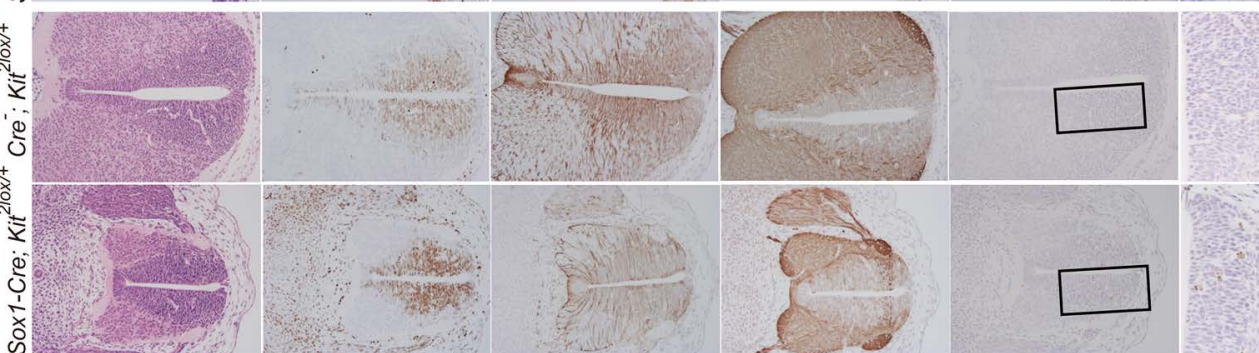

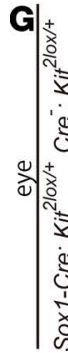

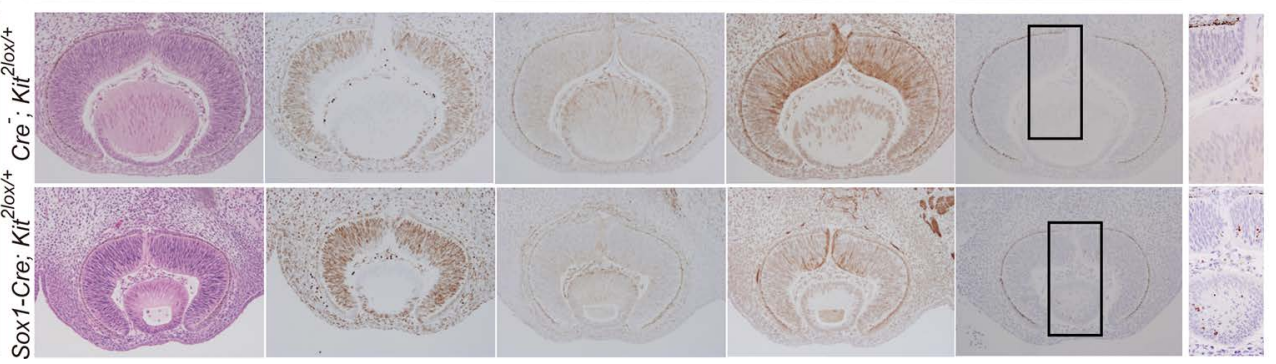

Figure 3. Histological characterization of the E12.5 Sox1-Cre; Kit ${ }^{210 x /+}$

embryos. (A) Sox1-Cre; Kit ${ }^{2 l o x /+}$;

Rosa26R-EYFP embryos and control Sox1-Cre; $\mathrm{Kit}^{+/+}$; Rosa26R-EYFP embryos were photographed using a fluorescence microscope. EYFP expression was markedly reduced in Sox1-Cre; Kit ${ }^{210 x /+}$; Rosa26R-EYFP embryos and clear brain hypoplasia of the telencephalon (indicated by arrowheads) was observed. (B-D) Embryos were sectioned at the indicated lines shown in $\mathbf{A}$. The telencephalon (black arrowheads in B) and metencephalon (white arrowheads in $\mathbf{B}$ and $\mathbf{C}$ ) had degenerated in Sox1-Cre; Kit ${ }^{2 l o x /+}$ embryos, while the nasal cavity (black arrowheads in C) and other non-neural tissues maintained their size and integrity. The spinal cord had also degenerated in Sox1-Cre; $\mathrm{Kit}^{2 / 10 x /+}$ embryos, while the size of the dorsal root ganglia did not change in Sox1-Cre; $\mathrm{Kit}^{2 \mathrm{lox} /+}$ embryos. T, telencephaIon; M, mesencephalon; NC, nasal cavity; DRG, dorsal root ganglia. (E-C) Histological analysis of E12.5 Sox1-Cre; Kit ${ }^{2 / 0 x /+}$ brains and ocular tissues. Individual TUNEL ${ }^{+}$cells in the squared regions are enlarged in the rightmost panels. Scale bars: $500 \mu \mathrm{m}$ in B-D; $100 \mu \mathrm{m}$ in E. HE, hematoxylin and eosin.

Brain hypoplasia became more evident in E15.5 Sox1-Cre; Kit ${ }^{2 l o x /+}$ embryos. The brain developed a large hollow cavity and many brain structures showed obvious degeneration (Figure 4, A and B). In these regions, $\mathrm{Ki}^{+} 7^{+}$cells, nestin ${ }^{+}$cells, and Tuj ${ }^{+}$cells were distributed in the subventricular zone and ependymal layer, as they were in the controls (Figure 4, C and D), and apoptotic cells were no longer detected (Figure 4, C and D). Hypoplasia of the spinal cord was most evident in the cervical region close to the myelencephalon (Figure 4B). The size of the spinal cord was also reduced in Sox1-Cre; Kit $t^{2 l o x /+}$ embryos, although $\mathrm{Ki}^{2} 7^{+}$cells, nestin ${ }^{+}$cells, and Tuj $1^{+}$cells were maintained in proportionally similar ratios to those seen in control animals (Figure 4E) and apoptotic cells were present at very low levels (Figure 4E). These characteristics of Sox 1-Cre; Kit ${ }^{2 l o x /+}$ brain structure and head morphology were also observed in E18.5 (Supplemental Figure 5) and P0 embryos. Quantitative analysis of the number of $\mathrm{TUNEL}^{+}$and $\mathrm{Ki}^{+} 7^{+}$cells in various brain tissues at each developmental stage confirmed the above observations (Supplemental Figure 6). In $\mathrm{Kit}^{W /+}$ and $\mathrm{Kit}{ }^{W / W}$ newborn mice, head morphology was indistinguishable from that of wild type (Supplemental Figure 7). We suggest that the antiproliferative effect of Kit haploinsufficiency is limited to the E12.5 developmental stage and that the initial reduction of the proliferative activity could not be compensated for in later developmental stages.

Proliferative embryonic neural stem cells were clearly present in Sox1-Cre-induced Kit haploinsufficient E12.5 embryos. It appears that successive transiently amplifying cells may have been eliminated during the apoptotic event after E12.5 in developing brain and spine. The apoptotic event appeared to be complete by 
stage E15.5, likely leaving an insufficient number of stem cells to repopulate brain structures. In addition, it is also likely that surviving stem cells could not properly proliferate and differentiate in the hypoplastic brain environment of Sox1-Cre; Kit ${ }^{2 l o x /+}$ mice.

Sox1-Cre-induced Kit haploinsufficiency impairs in vitro long-term self-renewal and immediate differentiation of neural stem cells. Sox 1 is one of the earliest transcription factors expressed in ectodermal cells committed to a neural fate $(19,20)$. Sox1 continues to be expressed in activated neural stem or progenitor cells in the adult brain $(21,22)$. To test the possibility that neural stem/progenitor cells are among the first cells affected by reduced levels of Kit (induced Kit haploinsufficiency), we generated neurospheres from the brains of Sox1-Cre; $\mathrm{Kit}^{2 l o x /+}$ embryos. For E10.5 brains, primary neurospheres were formed with equal frequency from Sox1-Cre; $\mathrm{Kit}^{2 \mathrm{lox} /+}$ and control embryos (Figure 5A), and the cumulative number of cells constituting neurospheres was also comparable (Figure 5, B and C). Although the numbers of primary neurospheres generated from E11.5 brains was also similar for Sox1-Cre; Kit ${ }^{2 l o x /+}$ and control embryos, (Figure 5D), the cumulative number of cells gradually declined in Sox1-Cre; Kit2lox/+ neurospheres (Figure 5, E and F). For E12.5 and E13.5 brains, the numbers of the primary neurospheres were again similar (Figure 5, G and J), and the reduction in Sox1-Cre; Kit ${ }^{2 l o x /+}$ neurosphere proliferation became more substantial (Figure 5, H, I, $\mathrm{K}$, and L). Normal proliferation of E10.5 Sox1-Cre; Kit ${ }^{2 l o x /+}$ neurospheres followed by the reduction of their cumulative proliferation in E11.5 or later neurospheres may coincide with the onset of brain hypoplasia detected in E11.5 brains and thereafter (Supplemental Figure 8, A and B).

We transferred these established neurospheres to a differentiation medium with serum and then colonies containing Tuj $1^{+}$or $\mathrm{GFAP}^{+}$cells were counted. While primary neurospheres from E10.5 and 11.5 embryos did not show any significant differences (Figure 6, A-D), a significant reduction of colonies containing Tuj $1^{+}$or $\mathrm{GFAP}^{+}$cells was observed in Sox1-Cre; Kit 2lox/+_-derived neurospheres from E12.5 and E13.5 brains (Figure 6, E-H).

We conclude that $K i t$ haploinsufficiency first reduces the long-term self-renewal capacity of induced neurospheres, and then impairs their ability to differentiate into neural cells. This may explain the observed in vivo reduction of differentiated Tuj $1^{+}$neurons in Sox1-Cre; Kit $t^{2 l o x /+}$ brains.

\section{Discussion}

The deleterious effects we see in the differentiation of Sox1-Cre-induced Kit-haploinsufficient ES cells into neuronal and glial cells, and the impaired brain development in Sox1-Cre-induced Kit-haploinsufficient mice, have not previously been observed in Kit or Kitl mutants. Indeed, $K i t^{W /+}$ or $K i t^{W / W}$ germline Kit loss-of-function mutant-derived ES cell lines showed a comparable in vitro derivation of neuronal and glial cells with those of wild-type ES cells. In contrast, Sox1-Cre; Kit ${ }^{2 l o x /+}$ mice showed a clear lethal phenotype, likely caused by extreme hypoplasia seen in the central nervous system, including the brain, ocular tissue, and spinal cord.

Kit expression is seen in undifferentiated ES cells and 2-cell embryos (23), and Kit expression in the brain is detectable from E8.5 (11). Defects in brain development first became detectable in E12.5 embryos as a hypoplasia of the brain and an increase in TUNEL ${ }^{+}$cells accompanied by the loss of Tuj $1^{+}$ differentiated neurons (Figure 3). To investigate the immediate cause of lethality in Sox1-Cre-induced Kit-haploinsufficient mice, sphere-forming neural stem cells were derived from the embryonic brain. A marked reduction in long-term self-renewal activity was observed in neural stem cells from E11.5, but not E10.5, Sox1-Cre; Kit $t^{2 l o x /+}$ brain cells. In E11.5 or later Sox1-Cre; Kit2lox/+ brain-derived spheres, a decrease in in vitro derivation of neurons and glial cells was seen. These observations demonstrate that Kit plays a crucial role in brain development. Known Kit-dependent functions in neurons involved in spatial learning (24) and the axon guidance of commissural neurons (12), manifested in germline Kit mutants, seem not to be related to the defective brain development we observe in Sox1-Cre; Kit ${ }^{2 l o x /+}$ embryos.

Haploinsufficient embryonic lethality - seen in $\mathrm{D}_{114^{-/+}}(25)$ and $\operatorname{Sox} 17^{-{ }^{++}}(26)$ mice - has not previously been reported in heterozygous germline Kit mutations. Kit-haploinsufficiency effects are not restricted to neural cells, but are also seen in melanocytes. Unlike neural cells, various germline Kit mutations are known to reduce the viability of the melanocyte cell lineage, which manifests itself as a large white spot in the ventral skin of germline $\mathrm{Kit}^{\mathrm{W/+}}$ haploinsufficient mice $(8,27)$. The loss of skin melanocytes in Kit mutants was recovered by exogenous Kitl expression (28). In cases in which Kit haploinsufficiency was induced by the melanocyte lineage-specific Tyr-Cre driver, the total size of the white spot was far more extensive in Tyr-Cre; $\mathrm{Kit}^{2 l o x /+}$ skin than that in $\mathrm{Kit}^{\mathrm{W/+}}$ skin. Similar to the neural cells in Sox1-Cre; Kit ${ }^{2 l o x /+}$ embryos, melanocytes in Tyr-Cre; 
A

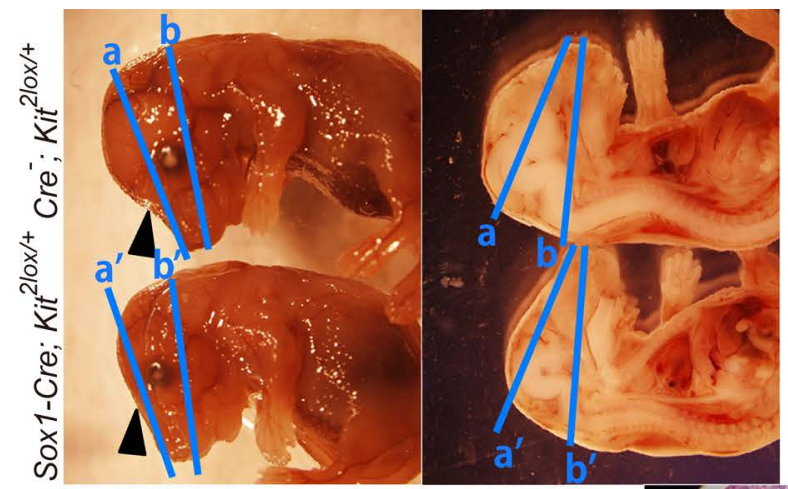

Figure 4. Histological characterization of the E15.5 Sox1-Cre; Kit ${ }^{20 x /+}$ embryos.

(A) The head region of E15.5 Sox1-Cre; Kit ${ }^{210 \times /+}$ and control embryos. The parietal region (arrowheads in left panel) was reduced in size in Sox1-Cre; Kit ${ }^{210 \times /+}$ embryos. Sliced samples (right panels) indicate a severe reduction of brain areas in Sox1-Cre; Kit $210 x /++$ embryos. (B) Embryos were sectioned around the lines indicated in A. In Sox1-Cre; Kit ${ }^{2 l o x /+}$ embryos, most areas of the brain had degenerated in comparison with normal counterparts. (C-E) Histological analysis of E15.5 Sox1-Cre; Kit $210 x /++$ brains and spinal cords. The indicated subventricular zone (C), ependymal layer (D), and spinal cord (E) in Sox1-Cre; Kit $t^{2 l o x /+}$ embryos could not be definitively identified since most areas of the brain were deformed. Scale bars: $500 \mu \mathrm{m}$ in B; $100 \mu \mathrm{m}$ in C. HE, hematoxylin and eosin.
B

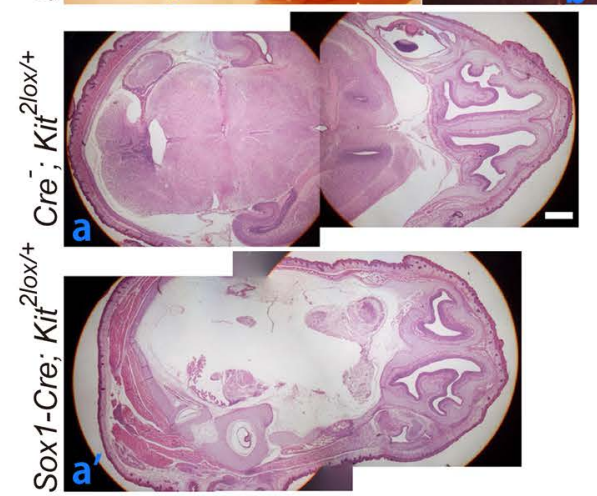

C

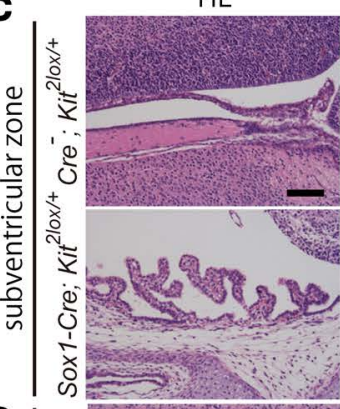

Ki67
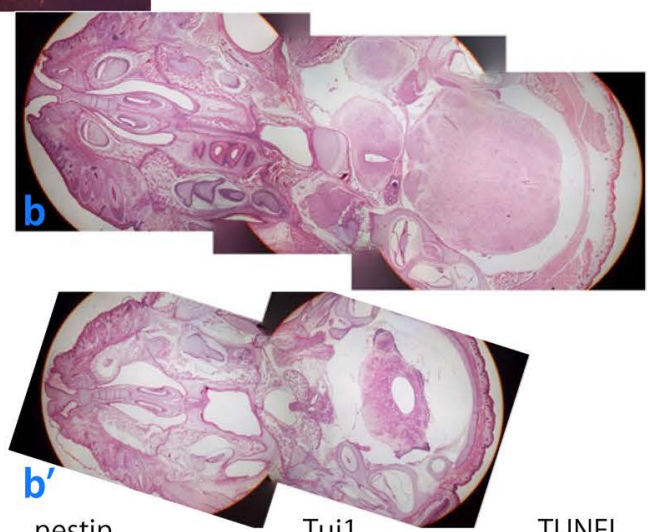

nestin

Tuj1

TUNEL
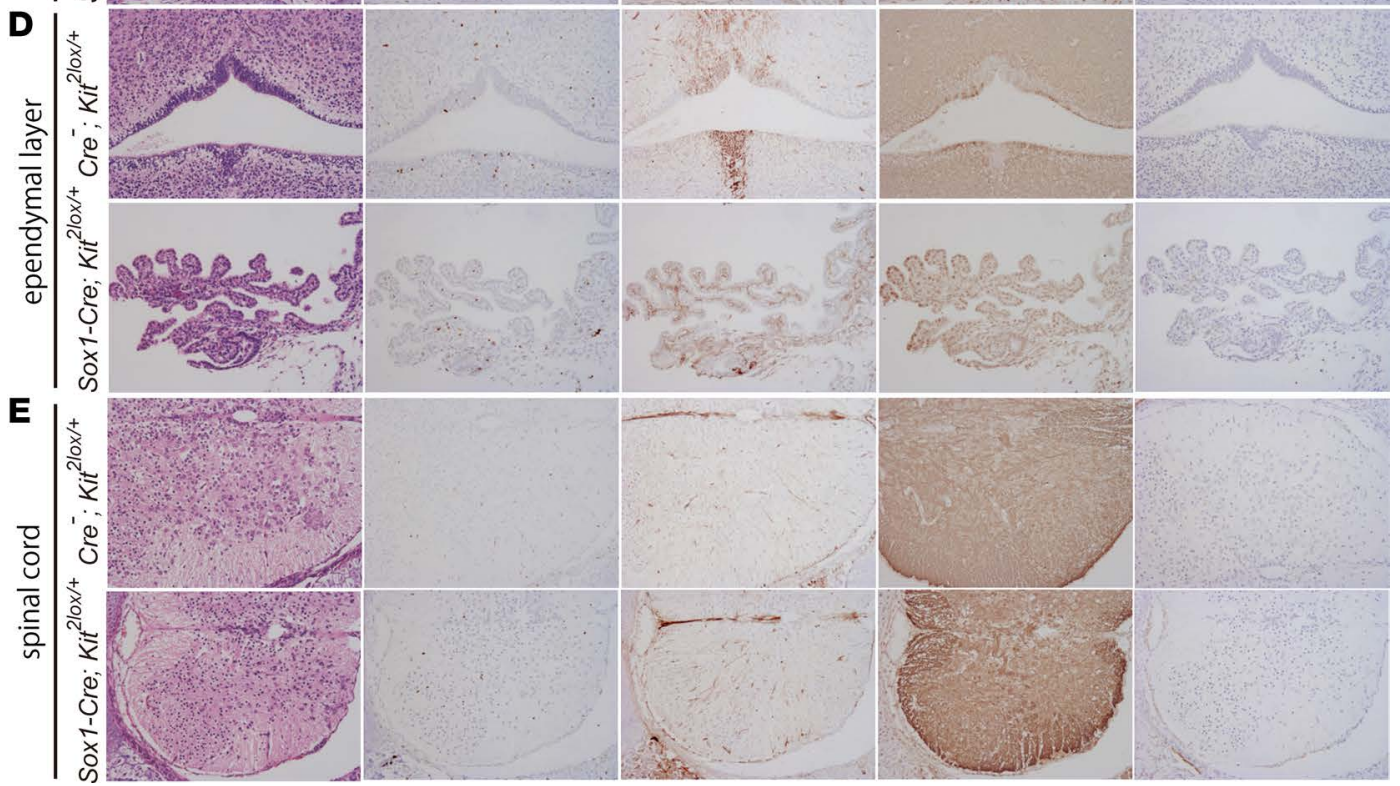
A

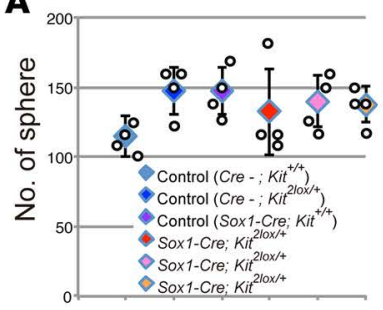

ำ
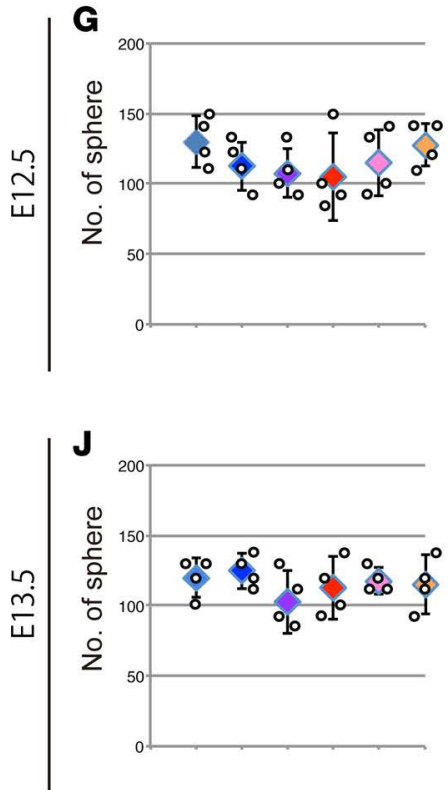

B

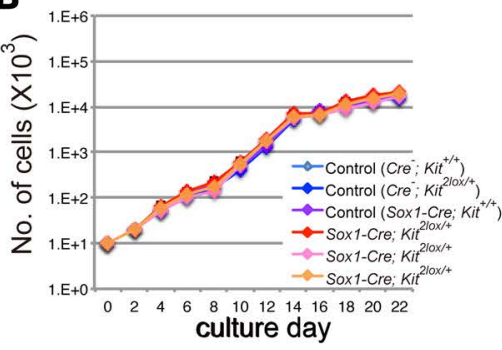

\section{E}

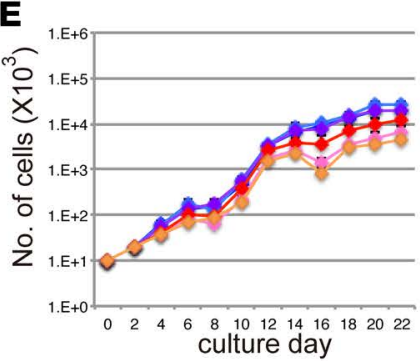

H

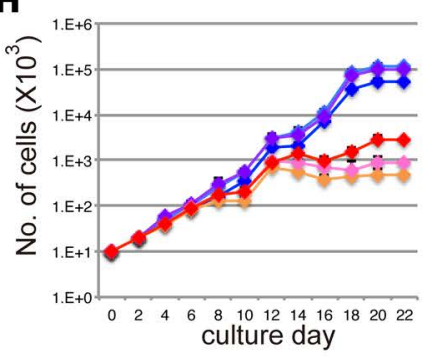

K

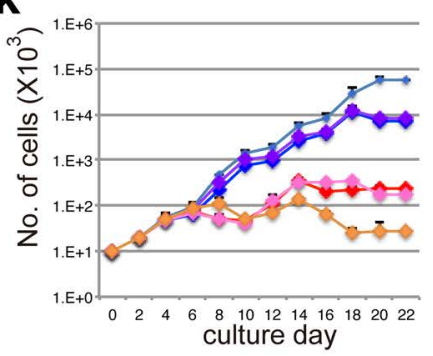

C

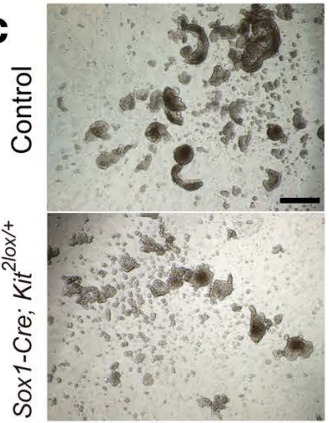

F

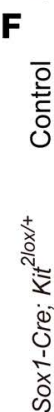

I
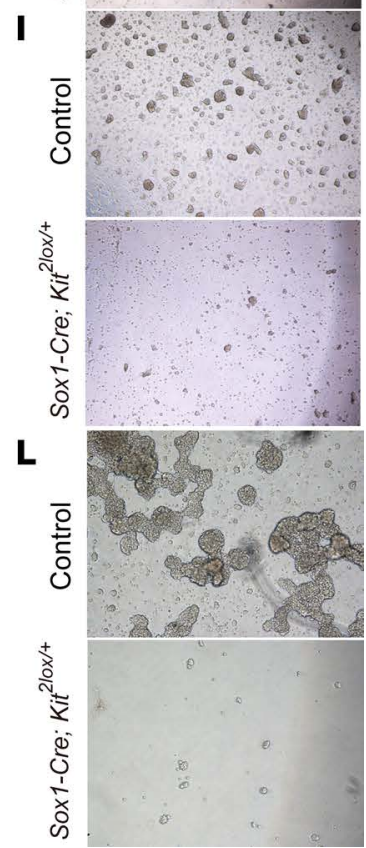

Figure 5. Reduction of the in vitro proliferative potential of neural stem cells from Sox1-Cre; $\mathrm{Kit}^{2 \mathrm{lox} /+}$ embryos at E10.5 or later developmental stages. (A) Brains were dissected from 6 E10.5 embryos and $1 \times 10^{4}$ cells were cultured to form neurospheres. Primary neurospheres were formed in comparable quantities from 3 Sox1-Cre; Kit ${ }^{2 l o x /+}$ brains and 3 control brains. (B) Growth curves of neurospheres from the 6 embryos in A. Neurospheres formed in $\mathbf{A}$ were dissociated and $1 \times 10^{4}$ cells were cultured and passaged every other day. (C) Neurospheres formed after 11 passages were photographed. Neurosphere analysis was similarly performed in brains from E11.5 (D-F), E12.5 (G-I), and E13.5 (J-L) embryos. The size of each neurosphere after 11 passages was substantially decreased in E11.5 or later Sox1-Cre; Kit ${ }^{210 x /+}$ brains (C, F, I, and $\mathbf{L})$. Error bars show \pm SD (the experiments were performed in triplicate). Scale bar: $100 \mu \mathrm{m}$.

$K i t^{2 l o x /+}$ embryos were affected by conditional Kit haploinsufficiency, first observed as a reduction of the melanocyte precursors in E15.5 Tyr-Cre; Kit ${ }^{2 l o x /+}$ skin (Figure 3 in ref. 14) and the comparative coat color phenotypes of representative Tyr-Cre; $\mathrm{Kit}^{2 l o x /+}$ and $\mathrm{Kit}^{\mathrm{W/+}}$ mice is also shown in Supplemental Figure 9). A developmental stage-specific mutation of the Kit regulatory sequence necessary for neural cell-specific expression should have the same haploinsufficient lethal phenotype in the induced and the spontaneous mutant. Naturally, we would not be aware of this type of noninheritable, dominant lethal mutation. It is likely that developmental stage-specific haploinsufficiency is actually taking place to cause embryonic death in general.

A functionally redundant gene product(s) must compensate for the reduced Kit dosage in the $\mathrm{Kit}^{\mathrm{W/+}}$ brain to ensure normal brain development. The same gene product(s) does not compensate for the reduced Kit dosage in the Sox1-Cre; $\mathrm{Kit}^{2 l o x /+}$ brain, perhaps because wild-type levels of Kit expression have been maintained until induction of Sox1-driven Cre expression, suppressing the activation of the compensatory gene(s) (Supplemental Figure 10. This form of negative feedback between functionally redundant proteins was proposed for duplicated genes in yeast; ref. 29). 
A

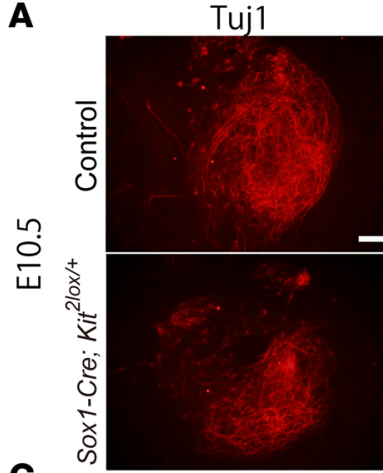

C

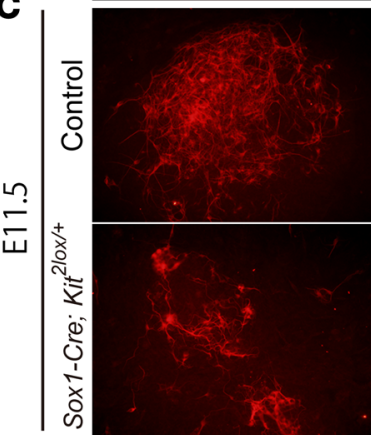

E
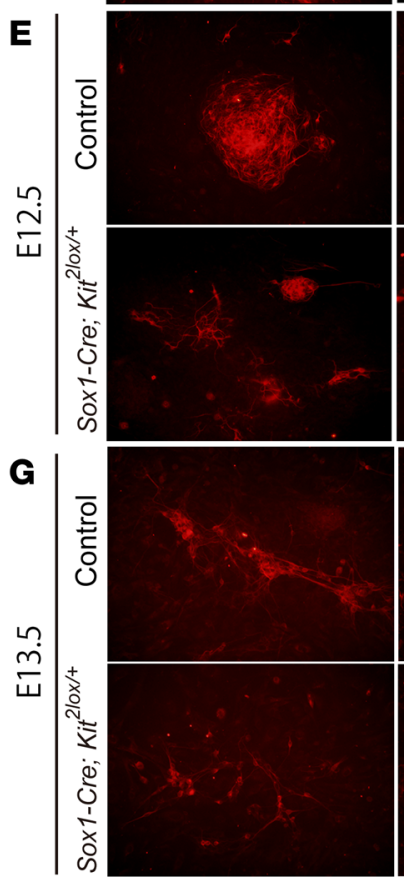
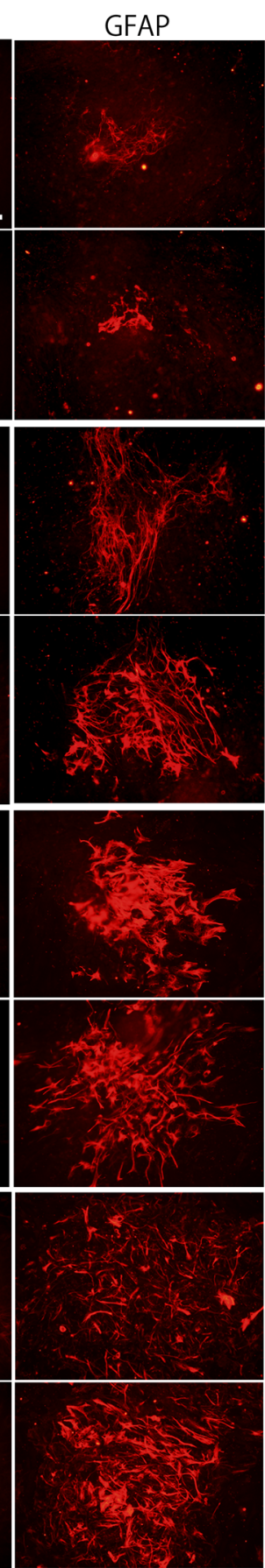

B
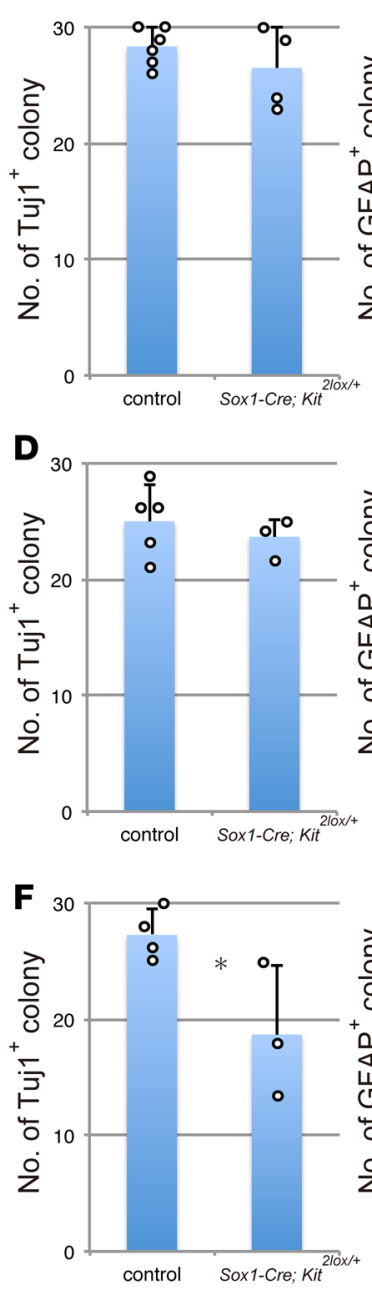

H

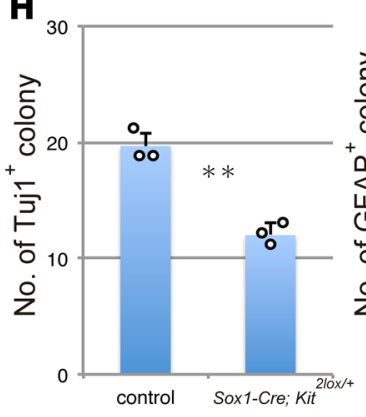

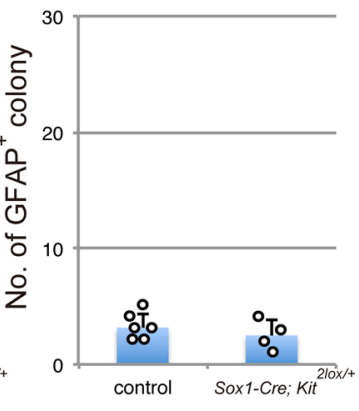
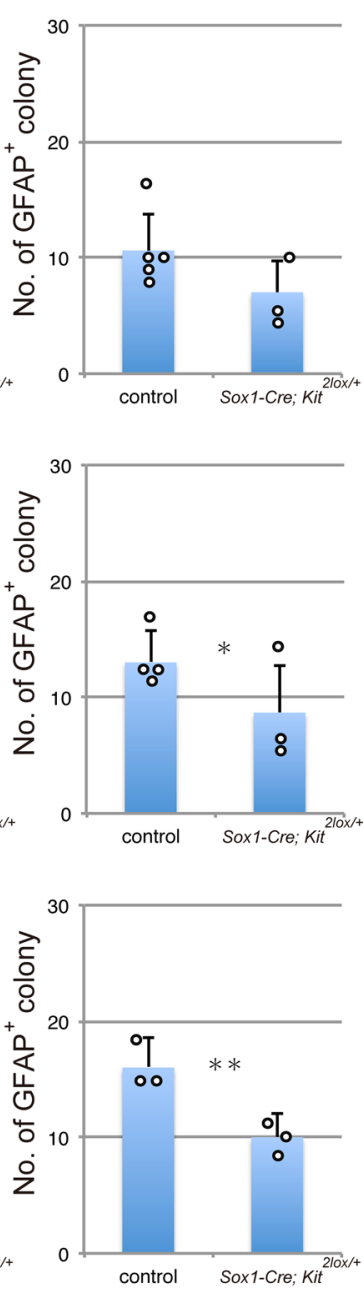

Figure 6. Neural cell dif-

ferentiation was reduced in neurospheres established

from E12.5 and E13.5 Sox1Cre; Kit ${ }^{2 l o x /+}$ brains. (A, C, E, and G) Immunocytochemical staining of neurospheres

in the differentiation condition. Thirty neurospheres established after 3 passages were transferred to differentiation medium supplemented with serum. One week after the adherent culture colonies appeared, cells were stained with the indicated marker. (B, D, F, and $\mathbf{H}$ ) The number of the colonies including Tuj $1^{+}$or $\mathrm{GFAP}^{+}$cells. A significant reduction of the number of colonies containing Tuj $1^{+}$or $\mathrm{GFAP}^{+}$cells was observed in neurospheres from Sox1-Cre; Kit tlox/+ $^{2}$ brains at E12.5 and

E13.5. Error bars show \pm SD ( $n=3$ for each embryo). ${ }^{*} P$ $<0.05$ and ${ }^{* *} P<0.01$ by 2 -tailed Student's $t$ test. Scale bar: $100 \mu \mathrm{m}$.

The $K i t^{1 l o x}$ allele resulting from the Cre-induced recombination in the $K i t^{2 l o x /+}$ allele is deprived of the transmembrane domain and has extra amino acids at its carboxyl terminus. The $\mathrm{Kit}^{W}$ allele has a mutation in intron 10 that, in mast cells, leads to partial exon 10 skipping and termination of the protein at a downstream stop codon, and in bone marrow and brain cells to the in-frame skipping of 3 exons (15). It is possible that Kit extracellular protein with a short extra peptide translated from the Kit ${ }^{\text {Ilox }}$ gene causes deleterious effects in developing neural cells. The $\mathrm{Kit}^{\mathrm{W} 42}$ loss-of-function mutant showed the most severely affected coat color phenotype in the haploinsufficient condition. The coat color phenotype of Tyr-Cre; $K i t^{2 l o x /+}$ is milder than that of $\mathrm{Kit}^{W 42 /+}$ and even this severe germline $\mathrm{Kit}^{\mathrm{W}{ }^{\mathrm{W} /+}}$ mutant shows no phenotype in brain development $(8,30)$. In addition, ES cells with a haploinsufficient $K i t^{1 l o x /+}$ genotype could be stably maintained in their proliferative and undifferentiated state, strongly suggesting a nontoxic effect of the 
defective $\mathrm{Kit}^{110 x}$ protein. Thus, we believe that the different phenotypes seen in Sox1-Cre; Kit ${ }^{2 l o x /+}$ and Tyr-Cre; $\mathrm{Kit}^{2 l o x /+}$ mice are not simply due to differences in the C-termini of the truncated proteins.

The administration of recombinant Kitl or anti-Kit antibodies during neural cell development has been shown to influence in vitro outgrowth of neurites and survival of neurons (31), postnatal cerebellum development (32), induction of long-term potentiation of hippocampal neurons (33), proliferation of neuronal precursors in the subventricular zone (34), cerebral cortical cell survival (35), and regeneration of olfactory neurons (36). We attribute the absence of these phenotypes in $\mathrm{Kit}^{\mathrm{W/+}}$ mice to the presence of a functionally redundant Kit-counterpart protein. In summary, our findings provide evidence that Kit signaling is functional in the early development of neural cells, and supports the idea that Kit regulates neural cell development and homeostasis.

\section{Methods}

Mice. $\mathrm{Kit}^{2 l o x /+}$ mice were generated from $\mathrm{Kit}^{2 l o x /+}$ ES cells line as previously described (14). Rosa26::rtTA; Col1a1::tetO-Cre mice (37, 38), Sox1-Cre mice (16), and Rosa26R-EYFP mice (39) were bred with Kit ${ }^{2 l o x /+}$ mice to generate compound transgenic mice. $K i t^{W}$ and $K i t^{W v}$ mice were obtained from Japan SLC. All mice were housed in standard animal rooms with food and water ad libitum under controlled humidity (50\% $\pm 10 \%$ ) and temperature $\left(22^{\circ} \mathrm{C} \pm 2{ }^{\circ} \mathrm{C}\right)$ conditions. The room was illuminated by fluorescent lights that were on from 8:00 AM to 8:00 PM. For embryo timing, vaginal plugs were checked and the day a plug was detected was considered E0.5.

Derivation of ES cell lines. The conditional Kit-knockout ES cell line containing doxycycline-inducible Cre alleles was generated from mouse E3.5 embryos that contain conditional Kit-knockout (Kit ${ }^{2 l o x}$ ) alleles (14) together with both the Rosa26::rtTA allele and Cola1::tetO-Cre allele (40) as previously described (38). The neural lineage-specific Kit conditional knockout ES cell line containing Cre-mediated recombination of Kit alleles by the Sox 1 promoter was derived from mouse E3.5 embryos that contained Kit ${ }^{2 l o x}$ alleles together with the Sox1-Cre allele by standard methods. $\mathrm{Kit}^{+/+}, \mathrm{Kit}^{W /+}$, and $\mathrm{Kit}^{W / W}$ ES cell lines were also generated from E3.5 embryos crossed with $\mathrm{Kit}^{w /+}$ mice by standard methods.

ES cell culture. Mouse ES cells were maintained under conditions previously described with minor modifications (37). Briefly, mouse ES cells were cultured under self-renewal conditions on feeder cells in standard ES media (DMEM, Gibco) supplemented with 15\% fetal calf serum (FCS, Hyclone), $1 \times$ nonessential amino acids, $2 \mathrm{mM}$ L-glutamine, $100 \mathrm{U} / \mathrm{ml}$ penicillin, $100 \mathrm{mg} / \mathrm{ml}$ streptomycin (all from Gibco), $0.1 \mathrm{mM}$ $\beta$-mercaptoethanol (Sigma-Aldrich), and 1,000 U/ml leukemia inhibitory factor (ESGRO, Millipore) on $0.1 \%$ gelatin-coated tissue culture dishes.

With minor modifications, the method for the induction of neural lineage was the same as previously described $(41,42)$. For differentiation, 1,000 trypsinized ES cells were inoculated on a monolayer of PA6 cells previously seeded on 6 -well plates (BD Falcon). ES cells were induced to differentiate in $\alpha$-minimum essential medium ( $\alpha$-MEM, Invitrogen) supplemented with 10\% FCS (EQUITECH-BIO, Inc.). They were maintained in an atmosphere of $5 \% \mathrm{CO}_{2}$ and $95 \%$ air at $37^{\circ} \mathrm{C}$. Then, $40 \mathrm{pM}$ basic fibroblast growth factor (bFGF, R\&D Systems, Inc.) was added to the medium on day 0 , and $10 \mathrm{nM}$ dexamethasone (Sigma-Aldrich) was added on day 3 . The cultures were also exposed to $20 \mathrm{pM}$ cholera toxin (Wako) from days 0 to 3 , and the medium was changed every 3 days. In some experiments, $100 \mathrm{ng} / \mathrm{ml}$ recombinant Kitl (BioLegend) and $10 \mu \mathrm{g} / \mathrm{ml}$ rat monoclonal antibody ACK2, which can block Kit function $(42,43)$, were added into the culture on the indicated days. In the indicated experiment, Rosa26::rtTA; Col1a1::tetO-Cre; Kit ${ }^{2 l o x /+}$ ES cells were treated with $2 \mu \mathrm{g} / \mathrm{ml}$ doxycycline.

Culture of neurospheres. Pregnant female mice were sacrificed by cervical dislocation, and embryos were quickly put on ice. For neurosphere culture, the brains were collected and dissociated into single-cell suspensions by gentle pipetting. The inner part of the trunk region was collected for genotyping. Primary neurospheres were generated from $1 \times 10^{4}$ suspended brain cells/well in a 24-well plate in DMEM/F12 medium (Gibco) supplemented with 1× N2 (Invitrogen), 1× B27 (Invitrogen), $20 \mathrm{ng} / \mathrm{ml}$ epidermal growth factor (EGF, R\&D Systems, Inc.), and $20 \mathrm{ng} / \mathrm{ml}$ bFGF. Primary neurospheres were passaged every 2 days to generate secondary neurospheres and the number of cells constituting the neurospheres was counted before passaging. For the differentiation cultures of the neurospheres, the spheres were individually isolated and 30 neurospheres were inoculated into 6-well plates previously coated with fibronectin/laminin (both from Invitrogen) and cultured in DMEM/F12 supplemented with $1 \times$ B27 and 10\% FCS (Nichirei Bioscience). Most of the transferred neurospheres attached and formed colonies. 
Flow cytometric analysis and cell sorting. Methods for cell preparation and flow cytometric analysis were performed as previously reported in detail (42). Briefly, cell suspensions of the brain and spinal cord were collected and resuspended in staining medium (SM: PBS containing 3\% FCS). The dissociated cells were then blocked with rat anti-mouse Fc gamma receptor (clone 93, BioLegend) on ice for 30 to 40 minutes. After another wash with SM, the cells were stained with phycoerythrin (PE)-conjugated rat anti-mouse CD45 (clone 30-F11, BioLegend) on ice for 30 to 40 minutes, washed, and incubated with allophycocyanin (APC)-conjugated rat anti-mouse c-Kit (clone 2B8, BioLegend) on ice for 30 to 40 minutes. The cells were then washed and resuspended in SM containing $3 \mu \mathrm{g} / \mathrm{ml}$ propidium iodide (PI, Calbiochem) to exclude dead cells. All cell sorting and analyses were performed with a FACSAria dual-laser flow cytometer (BD Biosciences). PI-negative cells were analyzed for CD45-PE and Sox1-Cre; Rosa26R-EYFP. EYFP-positive/ CD45-negative cells were selected and analyzed for Kit-APC fluorescence.

Histology and immunostaining. Pregnant female mice were euthanized with an overdose of sodium pentobarbital $(200 \mathrm{mg} / \mathrm{kg})$. The embryos were enucleated and fixed by immersion overnight in 10\% formalin in phosphate buffer ( $\mathrm{pH}$ 7.2). Specimens were dehydrated with ethanol, soaked in xylene, and embedded in paraffin. Serial sections were prepared at a 3- $\mu \mathrm{m}$ thickness using a Leica RM2125RT microtome (Leica RM2125RT, Leica Microsystems Inc.) and stained with hematoxylin and eosin (H\&E).

For immunohistochemistry, we used a Mouse-To-Mouse HRP Ready-To-Use Kit (ScyTek Laboratories), according to the manufacturer's protocol, to detect the mouse monoclonal primary antibodies on the sections. All procedures were performed at room temperature. Briefly, after deparaffinization and rehydration in Tris buffer ( $\mathrm{pH}$ 7.4), specimens were incubated with $1 \% \mathrm{H}_{2} \mathrm{O}_{2}$ in methanol for 10 minutes to reduce the level of endogenous peroxidase, and then incubated with Super Block for 5 minutes, followed by the Mouse-To-Mouse Block for 30 minutes. After incubation with the primary antibodies for 1 hour at room temperature or at $4^{\circ} \mathrm{C}$ overnight, the specimens were incubated with UltraTek Anti-Polyvalent (ScyTek Laboratories) for 20 minutes, and then with UltraTek HRP (ScyTek Laboratories) for another 20 minutes. For detection of the goat or rabbit polyclonal primary antibodies, a HISTOFINE Simple Stain Mouse MAX PO Kit (Nichirei BioScience) was used according to the manufacturer's protocol.

For immunocytofluorescence analysis, cells were fixed with $4 \%$ paraformaldehyde in PBS for 15 minutes, made permeable by immersion in $0.1 \%$ Triton X-100 and $0.5 \%$ BSA in PBS for 60 minutes, washed in PBS, and blocked in $0.5 \%$ BSA in PBS for 60 minutes. Primary antibodies, diluted in $0.5 \%$ BSA in PBS, were then added and allowed to react for 60 minutes at room temperature. After having been washed in PBS, the cells were stained with the secondary antibodies in the same manner. Cells were examined by using an IX-71 fluorescence microscope (Olympus). The number of colonies containing cells stained by each primary antibody was counted in each well. Percentages of marker-positive cells were calculated after counting the total number of colonies in each well.

Antibodies. The following primary antibodies were used in this study: anti-mouse Tuj1 (1:5,000; BabCO, catalog MMS-435P, clone TUJ1), anti-GFAP (1:1,000; Dako-Cytomation, catalog Z0334), anti-mouse nestin (1:500; BD Bioscience, catalog 611659, clone 25), and anti-mouse Ki67 (1:500; Dako-Cytomation, clone TEC-3).

In situ TUNEL method. To detect apoptotic cells, TUNEL staining was performed as previously described (41). After incubation with $20 \mu \mathrm{g} / \mathrm{ml}$ proteinase K (Sigma-Aldrich), the serial sections used for H\&E staining were immersed in terminal deoxynucleotidyl transferase (TDT) buffer (30 mM Trizma base, $\mathrm{pH}$ 7.2, $140 \mathrm{mM}$ sodium cacodylate, $1 \mathrm{mM}$ cobalt chloride). TDT and biotinylated dUTP (both from Roche) were diluted in TDT buffer at a concentration of 0.15 e.u. $/ \mathrm{ml}$ and $0.8 \mathrm{nmol} / \mathrm{ml}$, respectively. The solution was placed on the sections and then incubated at $37^{\circ} \mathrm{C}$ for 60 minutes. The sections were covered with streptavidin peroxidase (DAKO) and stained with $\mathrm{DAB}$ as a substrate for the peroxidase. Finally, counterstaining was conducted using Mayer's hematoxylin.

Real-time RT-PCR. Total RNA was prepared using the RNeasy Plus Mini Kit (Qiagen) according to the manufacturer's instructions. The first strand cDNA was synthesized from $1 \mu \mathrm{g}$ of total RNA using the PrimeScript II 1st strand cDNA Synthesis Kit (Takara) with oligo-dT primers according to the manufacturer's instructions. Real-time PCR was performed with SYBR Premix EX Taq (Takara) using a Thermal Cycler Dice and a Real-Time System Software (Takara).

The relative expression levels of Kit transcripts were compared with the reference gene $\beta$-actin using the following mouse-specific primers: Kit exon 2 (forward, 5'-GCCACGTCTCAGCCATCTG-3'; reverse, 5'-GTCGCCAGCTTCAACTATTAACT-3'), Kit exon 10 (forward, 5'-AAATCCAGGCCCACACTCT-3'; reverse, 
5'-AGGTGAGCACCATCACAATG-3'), Kit exon 11 (forward, 5'-TGGAAGGTTGTCGAGGAGAT-3'; reverse, 5'-TTCTGGGAAACTCCCATTTG-3'), and $\beta$-actin (forward, 5'-GCTACAGCTTCACCACCACA-3'; reverse 5'-CTTCTGCATCCTGTCAGCAA-3').

Statistics. Data are presented as the mean \pm SD. The statistical differences in the mean values were evaluated using a 2-tailed Student's $t$ test after evaluation of variances (Microsoft Excel). $P$ values less than 0.05 or less than 0.01 were considered significant.

Study approval. All animal experiments were approved by the Animal Research Committee of Gifu University Graduate School of Medicine, Gifu, Japan.

\section{Author contributions}

$\mathrm{HA}$ and TK developed the concepts and designed experiments. HA and $\mathrm{AH}$ carried out experiments and data analysis. TK and HA wrote the manuscript and assembled the figures. All authors reviewed and edited the manuscript.

\section{Acknowledgments}

We thank Kenichi Tezuka, Tsutomu Motohashi, and all members of the TK laboratory for discussion and help. A part of the histological analysis was supported by Advanced Model Animal Supporting Platform, Ministry of Education, Culture, Sports, Science and Technology, Japan. This study was supported by a grant from Ministry of Education, Culture, Sports, Science and Technology, Japan (16H05367), and a grant from Gifu University graduate school of medicine.

Address correspondence to: Takahiro Kunisada or Htomi Aoki, Department of Tissue and Organ Development, Gifu University Graduate School of Medicine, 1-1 Yanagido, Gifu, 501-1194, Japan. Phone: 81.58.230.6477. Email: tkunisad@gifu-u.ac.jp (T. Kunisada), hito7ao@gifu-u.ac.jp (H. Aoki).

1. Lennartsson J, Rönnstrand L. Stem cell factor receptor/c-Kit: from basic science to clinical implications. Physiol Rev. 2012;92(4):1619-1649

2. Lev S, Blechman JM, Givol D, Yarden Y. Steel factor and c-kit protooncogene: genetic lessons in signal transduction. Crit Rev Oncog. 1994;5(2-3):141-168.

3. Cardoso HJ, Figueira MI, Correia S, Vaz CV, Socorro S. The SCF/c-KIT system in the male: Survival strategies in fertility and cancer. Mol Reprod Dev. 2014;81(12):1064-1079.

4. Kent D, Copley M, Benz C, Dykstra B, Bowie M, Eaves C. Regulation of hematopoietic stem cells by the steel factor/KIT signaling pathway. Clin Cancer Res. 2008;14(7):1926-1930.

5. Wehrle-Haller B. The role of Kit-ligand in melanocyte development and epidermal homeostasis. Pigment Cell Res. 2003;16(3):287-296

6. Bashamboo A, Taylor AH, Samuel K, Panthier JJ, Whetton AD, Forrester LM. The survival of differentiating embryonic stem cells is dependent on the SCF-KIT pathway. J Cell Sci. 2006;119(pt 15):3039-3046.

7. Yuzawa S, Opatowsky Y, Zhang Z, Mandiyan V, Lax I, Schlessinger J. Structural basis for activation of the receptor tyrosine kinase KIT by stem cell factor. Cell. 2007;130(2):323-334.

8. Geissler EN, McFarland EC, Russell ES. Analysis of pleiotropism at the dominant white-spotting (W) locus of the house mouse: a description of ten new W alleles. Genetics. 1981;97(2):337-361.

9. Motro B, van der Kooy D, Rossant J, Reith A, Bernstein A. Contiguous patterns of c-kit and steel expression: analysis of mutations at the W and S1 loci. Development. 1991;113(4):1207-1221.

10. Keshet E, et al. Embryonic RNA expression patterns of the c-kit receptor and its cognate ligand suggest multiple functional roles in mouse development. EMBO J. 1991;10(9):2425-2435.

11. Orr-Urtreger A, Avivi A, Zimmer Y, Givol D, Yarden Y, Lonai P. Developmental expression of c-kit, a proto-oncogene encoded by the W locus. Development. 1990;109(4):911-923.

12. Gore BB, Wong KG, Tessier-Lavigne M. Stem cell factor functions as an outgrowth-promoting factor to enable axon exit from the midline intermediate target. Neuron. 2008;57(4):501-510.

13. Milenkovic N, et al. Nociceptive tuning by stem cell factor/c-Kit signaling. Neuron. 2007;56(5):893-906

14. Aoki H, Tomita H, Hara A, Kunisada T. Conditional deletion of Kit in melanocytes: white spotting phenotype is cell autonomous. J Invest Dermatol. 2015;135(7):1829-1838.

15. Hayashi S, Kunisada T, Ogawa M, Yamaguchi K, Nishikawa S. Exon skipping by mutation of an authentic splice site of c-kit gene in W/W mouse. Nucleic Acids Res. 1991;19(6):1267-1271.

16. Takashima Y, et al. Neuroepithelial cells supply an initial transient wave of MSC differentiation. Cell. 2007;129(7):1377-1388

17. Ying QL, Stavridis M, Griffiths D, Li M, Smith A. Conversion of embryonic stem cells into neuroectodermal precursors in adherent monoculture. Nat Biotechnol. 2003;21(2):183-186.

18. Wood HB, Episkopou V. Comparative expression of the mouse Sox1, Sox2 and Sox 3 genes from pre-gastrulation to early somite stages. Mech Dev. 1999;86(1-2):197-201.

19. Aubert J, et al. Screening for mammalian neural genes via fluorescence-activated cell sorter purification of neural precursors 
from Sox1-gfp knock-in mice. Proc Natl Acad Sci U S A. 2003;100(suppl 1):11836-11841.

20. Pevny LH, Sockanathan S, Placzek M, Lovell-Badge R. A role for SOX1 in neural determination. Development. 1998;125(10):1967-1978.

21. Venere M, Han YG, Bell R, Song JS, Alvarez-Buylla A, Blelloch R. Sox1 marks an activated neural stem/progenitor cell in the hippocampus. Development. 2012;139(21):3938-3949.

22. Sottile V, Li M, Scotting PJ. Stem cell marker expression in the Bergmann glia population of the adult mouse brain. Brain Res. 2006;1099(1):8-17.

23. Bernex F, De Sepulveda P, Kress C, Elbaz C, Delouis C, Panthier JJ. Spatial and temporal patterns of c-kit-expressing cells in WlacZ/+ and WlacZ/WlacZ mouse embryos. Development. 1996;122(10):3023-3033.

24. Motro B, Wojtowicz JM, Bernstein A, van der Kooy D. Steel mutant mice are deficient in hippocampal learning but not longterm potentiation. Proc Natl Acad Sci U S A. 1996;93(5):1808-1813.

25. Krebs LT, Shutter JR, Tanigaki K, Honjo T, Stark KL, Gridley T. Haploinsufficient lethality and formation of arteriovenous malformations in Notch pathway mutants. Genes Dev. 2004;18(20):2469-2473.

26. Uemura M, et al. Sox 17 haploinsufficiency results in perinatal biliary atresia and hepatitis in C57BL/6 background mice. Development. 2013;140(3):639-648.

27. Mackenzie MA, Jordan SA, Budd PS, Jackson IJ. Activation of the receptor tyrosine kinase Kit is required for the proliferation of melanoblasts in the mouse embryo. Dev Biol. 1997;192(1):99-107.

28. Kunisada T, et al. Transgene expression of steel factor in the basal layer of epidermis promotes survival, proliferation, differentiation and migration of melanocyte precursors. Development. 1998;125(15):2915-2923.

29. Kafri R, Springer M, Pilpel Y. Genetic redundancy: new tricks for old genes. Cell. 2009;136(3):389-392.

30. Tan JC, Nocka K, Ray P, Traktman P, Besmer P. The dominant W42 spotting phenotype results from a missense mutation in the c-kit receptor kinase. Science. 1990;247(4939):209-212.

31. Hirata T, et al. Stem cell factor induces outgrowth of c-kit-positive neurites and supports the survival of c-kit-positive neurons in dorsal root ganglia of mouse embryos. Development. 1993;119(1):49-56.

32. Manova K, et al. c-kit receptor and ligand expression in postnatal development of the mouse cerebellum suggests a function for c-kit in inhibitory interneurons. J Neurosci. 1992;12(12):4663-4676.

33. Kondo T, Katafuchi T, Hori T. Stem cell factor modulates paired-pulse facilitation and long-term potentiation in the hippocampal mossy fiber-CA3 pathway in mice. Brain Res. 2002;946(2):179-190.

34. Jin K, Mao XO, Sun Y, Xie L, Greenberg DA. Stem cell factor stimulates neurogenesis in vitro and in vivo. J Clin Invest. 2002;110(3):311-319.

35. Mashayekhi F, Gholizadeh L. Administration of anti-c-kit antibody into the cerebrospinal fluid leads to increased cell death in the developing cerebral cortex. Saudi J Biol Sci. 2011;18(3):261-266.

36. Goldstein BJ, et al. Adult c-Kit(+) progenitor cells are necessary for maintenance and regeneration of olfactory neurons. J Comp Neurol. 2015;523(1):15-31.

37. Yamada Y, Aoki H, Kunisada T, Hara A. Rest promotes the early differentiation of mouse ESCs but is not required for their maintenance. Cell Stem Cell. 2010;6(1):10-15.

38. Aoki H, Hara A, Era T, Kunisada T, Yamada Y. Genetic ablation of Rest leads to in vitro-specific derepression of neuronal genes during neurogenesis. Development. 2012;139(4):667-677.

39. Srinivas S, et al. Cre reporter strains produced by targeted insertion of EYFP and ECFP into the ROSA26 locus. BMC Dev Biol. 2001;1:4.

40. Beard C, Hochedlinger K, Plath K, Wutz A, Jaenisch R. Efficient method to generate single-copy transgenic mice by site-specific integration in embryonic stem cells. Genesis. 2006;44(1):23-28.

41. Aoki H, Hara A, Motohashi T, Chem H, Kunisada T. Iris as a recipient tissue for pigment cells: organized in vivo differentiation of melanocytes and pigmented epithelium derived from embryonic stem cells in vitro. Dev Dyn. 2008;237(9):2394-2404

42. Aoki H, Yamada Y, Hara A, Kunisada T. Two distinct types of mouse melanocyte: differential signaling requirement for the maintenance of non-cutaneous and dermal versus epidermal melanocytes. Development. 2009;136(15):2511-2521.

43. Nishikawa $S$, et al. In utero manipulation of coat color formation by a monoclonal anti-c-kit antibody: two distinct waves of c-kit-dependency during melanocyte development. EMBO J. 1991;10(8):2111-2118. 